\title{
Global \& Community Health: Brief in-hospital cognitive screening anticipates complex admissions and may detect dementia
}

David Bissig, MD, PhD, and Charles S. DeCarli, MD

Neurology ${ }^{\circledR}$ 2019;92:631-634. doi:10.1212/WNL.0000000000007176
Correspondence

Dr. Bissig

bissig@ohsu.edu

\section{Abstract}

\section{Objective}

With the long-term goal of improving community health by screening for dementia, we tested the utility of integrating the Six-Item Screener (SIS) into our emergency department neurology consultations.

\section{Methods}

In this cross-sectional observational study, we measured SIS performance within 24 hours of hospital arrival in 100 consecutive English-speaking patients aged $\geq 45$ years. Performance was compared to patient age, previously charted cognitive impairment, and proxies for in-hospital complexity: whether or not a patient was admitted to the hospital and the number of medical studies ordered.

\section{Results}

Those with poor SIS performance were older $(p=0.02)$ and more likely to have previously charted cognitive impairment $(p<0.01$; sensitivity $86 \%$, specificity $77 \%)$. Poor performers were more likely to be admitted to the hospital $(p=0.04$; odds ratio 3.6$)$ and were subjected to more tests once admitted $(p<0.01)$, relationships that persisted after accounting for age and history of cognitive impairment.

\section{Conclusions}

Poor performance on the SIS was associated with previously charted cognitive impairment, justifying future study of its ability to detect unrecognized dementia cases. Until then, its ability to inexpensively anticipate medically complex hospital admissions motivates broader emergency department use of the SIS. 


\section{Glossary}

ED = emergency department; LOS = length of stay; $\mathbf{M C I}=$ mild cognitive impairment; $\mathbf{M M S E}=$ Mini-Mental State Examination; OR = odds ratio; QI = quality improvement; SIS = Six-Item Screener.

Without intensive outpatient screening of community-dwelling adults, $65 \%-82 \%$ of cases of cognitive impairment go unrecognized. ${ }^{1,2}$ Community health efforts to identify dementia may be fruitful in the emergency department (ED). The chronic health conditions and poor socioeconomic status associated with dementia also predispose to ED visits, ${ }^{3,4}$ and cognitive impairment increases the risk of hospitalization. ${ }^{5}$ Moreover, the acute illness triggering the ED visit may strain cognitive reserve, worsen test performance, and thereby improve screening sensitivity (perhaps at the expense of specificity). An ED screen should be brief, easy to implement, retain fair sensitivity and specificity for cognitive impairment, and integrate with ED providers' typical scope of care, which includes risk stratification during the acute illness. For these reasons, we investigated routine use of the Six-Item Screener (SIS) during our initial inhospital encounters with patients. The SIS tests orientation and word recall, adds less than a minute to an examination, and compares favorably with the Mini-Mental State Examination (MMSE) in outpatient ${ }^{6}$ and ED settings. ${ }^{7}$

\section{Methods}

In the second half of 2016, we collected data for a quality improvement (QI) project promoting routine SIS use by the University of California-Davis Neurology Consultation Service. For a new consultation, residents were asked to use the SIS if a patient was $\geq 45$ years old, communicated in spoken English, and had been in the hospital for less than 24 hours. No qualifying patients were excluded. SIS performance was logged in electronic medical records, and data were later anonymized and extracted for analysis. The goal was to test whether resident SIS use helped characterize patients' prehospitalization or in-hospital well-being. The study proposal was exempted from full review by the University of California-Davis institutional review board.

Measures of prehospitalization well-being were age, the number of home medications, and whether a patient had a previously documented diagnosis of cognitive impairment, either dementia or mild cognitive impairment (MCI). Measures of in-hospital well-being included vital signs, whether or not a patient was admitted to the hospital from the $\mathrm{ED}$, and of those patients that were admitted, their length of stay (LOS) and how many studies (imaging plus laboratory studies) were ordered during their admission.

To administer the SIS, one tests free recall of 3 spoken words (herein, "banana," "sunrise," and "chair") and asks the patient the month, the year, and the day of the week. One point is awarded for each correct orientation question and for each freely recalled word after a short ( $>1$ minute) delay, for a total of 6 points. For this QI project, judgement on its use- whether mental status and English proficiency were sufficient, whether it should be skipped (as in the setting of a stroke code) - and the choice of distraction task between word registration and recall (usually clock drawing; for frequency, see dataset S1, doi.org/10.5061/dryad.gn8h3tg) was at the discretion of the neurology resident. Nevertheless, residents were encouraged by near-daily reminders, and based on their feedback and the time interval needed to assess 100 patients, SIS use was thought to be near-universal for eligible patients.

Based on community SIS performance in Callahan et al., ${ }^{6}$ we chose a target enrollment of 100 patients, and to dichotomize SIS performance as poor (score 0-3) or good (4-6). Based on their data, dichotomized this way, a $\chi^{2}$ test comparing SIS performance to the presence of dementia would require 49 patients to achieve a power of 0.80 (with $\alpha=0.05$ ). The higher target enrollment accommodated analyses of in-hospital wellbeing and uncertain dementia prevalence in our population.

As there is wide literature variability on how to dichotomize SIS performance-with "good" performance requiring no errors in some contexts, ${ }^{1}$ or allowing 3 errors in others ${ }^{8}$-we provide raw scores (dataset S1, doi.org/10.5061/dryad.gn8h3tg).

\section{Statistical analysis}

Continuous data are reported as mean \pm SD. For inferential statistics, number of studies and LOS were log-transformed to reduce skew. Depending on whether variables were categorical or continuous, comparisons were based on Fisher exact test, Welch $t$ test, or a generalized linear model. A 2-tailed $p<0.05$ was considered significant.

\section{Results}

Our 100 patients were aged $68 \pm 12$ years. Fifty-nine were men. Six patients had previously documented cognitive impairment (5 with dementia; 1 with $\mathrm{MCI}$ ). Seventy-four patients were admitted to the hospital. The primary reason (diagnosis/complaint) for each ED visit is provided in dataset S1 (doi.org/10.5061/dryad.gn8h3tg). Admitted patients had a LOS of $4.0 \pm 4.0$ days. For patients admitted to the hospital, $38 \pm 30$ studies were ordered per patient. Much of the variance in studies ordered was related to length of stay ( $p<$ $\left.0.001 ; R^{2}=0.46\right)$.

Those with poor SIS performance were older $(p=0.021 ; 73 \pm$ 13 vs $66 \pm 11$ years) and more likely to have previously documented cognitive impairment ( 5 of 27, compared to 1 of the 73 good performers; $p=0.005$, odds ratio $[\mathrm{OR}] 15.8$ ). The 
relationship persisted when analysis was restricted to those aged $\geq 65$ years $(p=0.012)$.

Comparing prehospital to in-hospital well-being, there was no relationship between the odds of admission, the number of studies ordered during an admission, or the LOS to either patient age or the number of home medications (all $p>0.1$ ). Similarly, a preexisting diagnosis of cognitive impairment was related neither to the odds of admission nor the number of studies ordered (both $p>0.1$ ).

Those with poor SIS performance were more likely to be admitted to the hospital ( 24 of 27 poor performers and 50 of 73 good performers admitted; $p=0.043$; OR 3.6). Of those admitted, poor SIS performance was unrelated to LOS $(p>$ $0.5)$, but was associated with more studies ordered during the hospitalization $(p=0.019)$. This finding remained after adjusting for LOS, regardless of whether patients with cognitive impairment were included or excluded, and whether age (which was not predictive in any model; $p>0.2$ ) was included as a variable $\left(F_{1,71}\right.$ [or $F_{1,65}$ when excluding previously documented cognitive impairment] $>9.70, p<0.003)$.

\section{Discussion}

In this study, we used the SIS to rapidly screen patients for poor cognition during an acute hospital visit. In this environment, SIS performance retained fair sensitivity and specificity for previously documented cognitive impairment. However, poor performance was found in $27 \%$ of our patients, of which the majority had no known baseline cognitive impairment.

As a QI project to promote routine use of the SIS, our study did not carefully control the testing environment, was broadly inclusive of ages and diagnoses, and the SIS was administered at the discretion of whichever resident was on service. These factors increase variability and would be undesirable for the initial validation of the SIS, but such validation studies already exist for the ED setting. ${ }^{7,9}$ Our report adds ecological validity, demonstrating the real-world utility of the SIS. Poor SIS performance was associated with greater likelihood of admission and more diagnostic testing (figure). Perhaps cognition is worse in sicker patients, who will require more diagnostic workup because of the severity of their medical illness. However, we cannot exclude the possibility that the act of screening for (and documenting) cognitive symptoms itself inspired well-justified additional workup. Regardless, SIS performance measured early in a hospital visit can risk-stratify patients, reminiscent of findings for the MMSE. ${ }^{10}$ This utility, combined with the simplicity and brevity of the SIS, makes it appealing for widespread use in community EDs.

Because we analyzed single-site data from our neurology consultation service, we recognize that rates and underlying etiologies of poor cognition may differ in other settings, limiting generalizability of the present findings. We are reassured that our results are similar to a 2011 study that sought to enroll all ED
Figure Six-Item Screener (SIS) performance predicts the number of diagnostic studies ordered during hospitalization

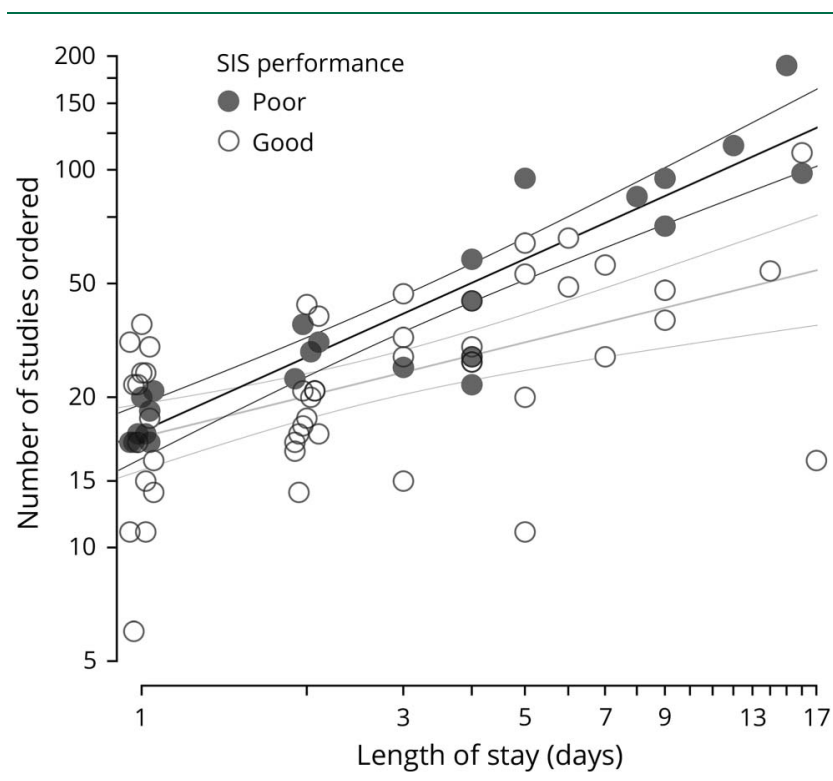

The number of studies is the sum of laboratory and imaging orders during an admission. For example, a patient receiving a chest x-ray, basic metabolic panel, and serum lactate would be counted as having 3 studies. In these analyses of patients admitted to the hospital, the number of studies increases with length of stay (LOS), and is predicted by SIS performance. To help visualize overlapping points on LOS of 1 and 2 days, points are jittered slightly around their integer $x$-axis value. The final model displayed here included the interaction between SIS performance and LOS $(p=0.012)$ : the intercept for both best-fit lines (shown with $\pm 95 \%$ confidence interval) is nearly identical, but poor performers have a steeper slope $(\ln [$ studies] $=0.65 * \ln [$ LOS] +3.0 vs $\ln$ [studies] $=$ $0.36 * \ln [\mathrm{LOS}]+3.0)(p=0.012$ for LOS $\times$ performance interaction). The full model of In(LOS) + SIS performance + the interaction explains $55 \%$ of the variance in $\ln$ (studies) $\left(R^{2}=0.553\right)$. Based on the best-fit lines, $\sim 40 \%$ more studies will be ordered on a poor performer than on a good performer during a 3-day hospitalization.

patients aged 65 years or older, which also found a significant relationship between SIS score and previously diagnosed dementia $^{10}$ : reanalyzing our data with that study's stricter age cutoff, higher SIS threshold for "good" performance, and need to have dementia (not just MCI) to count as cognitive impairment, we calculate a sensitivity and specificity of $80 \%$ and $52 \%$, compared to their $79 \%$ and $62 \%$. That SIS threshold may be too strict when screening for dementia in patients who are acutely ill. Half of our patients with previously documented cognitive impairment earned fewer than 2 points correct on the SIS. Community screening for unrecognized dementia cases might therefore select a lenient threshold, improving specificity while easily uncovering several patients who deserve additional cognitive assessment. At our preselected threshold, the SIS retained fair sensitivity and specificity for cognitive impairment in general ( $86 \%$ and $77 \%$ ) and dementia specifically (discounting the 1 patient with MCI; $80 \%$ and $76 \%$ ) in the setting of a hospital visit, compared to $89 \%$ and $88 \%$ measured in an outpatient sample. ${ }^{6}$

Outpatient follow-up would help identify the cause of poor performance on our single in-hospital screen. The possibility that poor SIS performance can identify previously 
Appendix Authors

\begin{tabular}{|c|c|c|c|}
\hline Name & Location & Role & Contribution \\
\hline $\begin{array}{l}\text { David } \\
\text { Bissig, } \\
\text { MD, PhD }\end{array}$ & $\begin{array}{l}\text { Oregon Health \& } \\
\text { Science } \\
\text { University, } \\
\text { Portland }\end{array}$ & Author & $\begin{array}{l}\text { Contributed to study } \\
\text { concept and design, } \\
\text { participated in the } \\
\text { acquisition of data (along } \\
\text { with other residents training } \\
\text { at UC-Davis Neurology), } \\
\text { analyzed the data, drafted } \\
\text { the manuscript for } \\
\text { intellectual content }\end{array}$ \\
\hline $\begin{array}{l}\text { Charles S. } \\
\text { DeCarli, } \\
\text { MD }\end{array}$ & $\begin{array}{l}\text { University of } \\
\text { California-Davis }\end{array}$ & Author & $\begin{array}{l}\text { Contributed to study } \\
\text { concept and design, revised } \\
\text { the manuscript for } \\
\text { intellectual content }\end{array}$ \\
\hline
\end{tabular}

unrecognized cognitive impairment is enticing, suggesting a role in community health initiatives to identify new dementia cases. Future studies of this type are warranted by the expectation that early identification of cognitive impairment could lead to reduced inpatient costs as well as better postdischarge management.

\section{Disclosure}

The authors report no disclosures relevant to the manuscript. Go to Neurology.org/ $\mathrm{N}$ for full disclosures.

\section{Study funding}

No targeted funding reported.

\section{References}

1. Boustani M, Callahan CM, Unverzagt FW, et al. Implementing a screening and diagnosis program for dementia in primary care. J Gen Intern Med 2005;20: $572-577$

2. Boise L, Neal MB, Kaye J. Dementia assessment in primary care: results from a study in three managed care systems. J Gerontol A Biol Sci Med Sci 2004;59: M621-M626.

3. Weber EJ, Showstack JA, Hunt KA, Colby DC, Callaham ML. Does lack of a usua source of care or health insurance increase the likelihood of an emergency department visit? Results of a national population-based study. Ann Emerg Med $2005 ; 45: 4-12$.

4. Walters K, Hardoon S, Petersen I, et al. Predicting dementia risk in primary care: development and validation of the Dementia Risk Score using routinely collected data. BMC Med 2016;14:6

5. Wilson RS, Rajan KB, Barnes LL, Hebert LE, Mendes de Leon CF, Evans DA Cognitive aging and rate of hospitalization in an urban population of older people. J Gerontol A Biol Sci Med Sci 2014;69:447-454.

6. Callahan CM, Unverzagt FW, Hui SL, Perkins AJ, Hendrie HC. Six-Item Screener to identify cognitive impairment among potential subjects for clinical research. Med Care 2002;40:771-781

7. Wilber ST, Lofgren SD, Mager TG, Blanda M, Gerson LW. An evaluation of two screening tools for cognitive impairment in older emergency department patients. Acad Emerg Med 2005;12:612-616.

8. Chen MR, Guo QH, Cao XY, Hong Z, Liu XH. A preliminary study of the SixItem Screener in detecting cognitive impairment. Neurosci Bull 2010;26 317-321.

9. Carpenter CR, DesPain B, Keeling TN, Shah M, Rothenberger M. The Six-Item Screener and $\mathrm{AD} 8$ for the detection of cognitive impairment in geriatric emergency department patients. Ann Emerg Med 2011;57:653-661.

10. Inouye SK, Peduzzi PN, Robison JT, Hughes JS, Horwitz RI, Concato J. Importance of functional measures in predicting mortality among older hospitalized patients. JAMA 1998;279:1187-1193. 


\title{
Neurology
}

\author{
Global \& Community Health: Brief in-hospital cognitive screening anticipates complex \\ admissions and may detect dementia \\ David Bissig and Charles S. DeCarli \\ Neurology 2019;92;631-634 \\ DOI 10.1212/WNL.0000000000007176
}

This information is current as of March 25, 2019

\section{Updated Information \&} Services

References

Subspecialty Collections

Permissions \& Licensing

Reprints including high resolution figures, can be found at: http://n.neurology.org/content/92/13/631.full

This article cites 10 articles, 0 of which you can access for free at: http://n.neurology.org/content/92/13/631.full\#ref-list-1

This article, along with others on similar topics, appears in the following collection(s):

Assessment of cognitive disorders/dementia

http://n.neurology.org/cgi/collection/assessment_of_cognitive_disorder S_dementia

\section{Clinical neurology examination}

http://n.neurology.org/cgi/collection/clinical_neurology_examination Neuropsychological assessment

http://n.neurology.org/cgi/collection/neuropsychological_assessment

Information about reproducing this article in parts (figures,tables) or in its entirety can be found online at:

http://www.neurology.org/about/about_the_journal\#permissions

Information about ordering reprints can be found online:

http://n.neurology.org/subscribers/advertise

Neurology ${ }^{\circledR}$ is the official journal of the American Academy of Neurology. Published continuously since 1951, it is now a weekly with 48 issues per year. Copyright (C) 2019 American Academy of Neurology. All rights reserved. Print ISSN: 0028-3878. Online ISSN: 1526-632X.

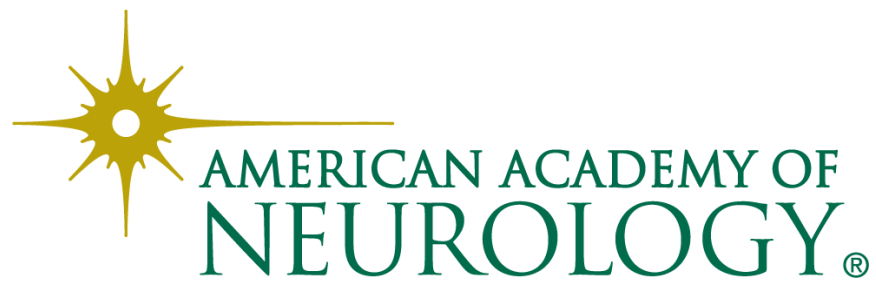

